plus SST. Primary endpoints: safety assessments. Key secondary endpoints: SRI4 response rate at each scheduled visit (observed data), defined as a $\geq 4$ point reduction from baseline in SELENA-SLEDAI score, no worsening in PGA (<0.3-point increase from baseline) and no new BILAG 1A/2B organ domain scores; time to first severe SFI flare over time. Endpoints were analysed relative to first BEL dose (parent or current study). No follow-up data were collected after study withdrawal.

Table.

\begin{tabular}{|c|c|c|c|c|c|c|c|c|}
\hline Endpoint, n (\%) & $\begin{array}{c}\text { Anytime } \\
\text { post } \\
\text { baseline } \\
\mathrm{N}=142\end{array}$ & $\begin{array}{c}\text { Year } 0-1 \\
n=142\end{array}$ & $\begin{array}{c}\text { Year 1-2 } \\
n=136\end{array}$ & $\begin{array}{c}\text { Year } \\
2-3 \\
n=108\end{array}$ & $\begin{array}{c}\text { Year } \\
3-4 \\
n=79\end{array}$ & $\begin{array}{c}\text { Year } \\
4-5 \\
n=32\end{array}$ & $\begin{array}{c}\text { Year } \\
5-6 \\
n=24\end{array}$ & $\begin{array}{c}\text { Year } \\
6+ \\
n=13\end{array}$ \\
\hline $\begin{array}{l}\geq 1 \mathrm{AE} \\
\geq 1 \text { severe } \mathrm{AE}\end{array}$ & $\begin{array}{l}139(97.9) \\
27(19.0)\end{array}$ & $\begin{array}{c}133 \\
(93.7) \\
12(8.5)\end{array}$ & $\begin{array}{c}122 \\
(89.7) \\
10(7.4)\end{array}$ & $\begin{array}{c}81 \\
(75.0) \\
7(6.5)\end{array}$ & $\begin{array}{c}59 \\
(74.7) \\
2(2.5)\end{array}$ & $\begin{array}{c}30 \\
(93.8) \\
1(3.1)\end{array}$ & $\begin{array}{c}24(100) \\
1(4.2)\end{array}$ & $\begin{array}{c}9 \\
(69.2) \\
0\end{array}$ \\
\hline $\begin{array}{l}\geq 1 \text { treatment-re- } \\
\text { lated } A E\end{array}$ & $81(57.0)$ & $46(32.4)$ & 38 (27.9) & $\begin{array}{c}20 \\
(18.5)\end{array}$ & $\begin{array}{c}11 \\
(13.9)\end{array}$ & $9(28.1)$ & $3(12.5)$ & $\begin{array}{c}1 \\
(7.7)\end{array}$ \\
\hline$\geq 1 \mathrm{SAE}$ & $48(33.8)$ & $24(16.9)$ & $18(13.2)$ & $9(8.3)$ & $6(7.6)$ & $2(6.3)$ & $3(12.5)$ & 0 \\
\hline $\begin{array}{l}\text { Serious infections } \\
\text { and infestations }\end{array}$ & $24(16.9)$ & $14(9.9)$ & $5(3.7)$ & $2(1.9)$ & $3(3.8)$ & 0 & $1(4.2)$ & 0 \\
\hline $\begin{array}{l}\text { Deaths } \\
\text { AESI }\end{array}$ & $1(0.7)^{\star}$ & 0 & 0 & 0 & 0 & 0 & 0 & 0 \\
\hline Malignancy & $1(0.7)$ & 0 & $1(0.7)$ & 0 & 0 & 0 & 0 & 0 \\
\hline Opportunistic & $10(7.0)$ & $3(2.1)$ & $4(2.9)$ & $1(0.9)$ & $1(1.3)$ & 0 & 0 & 0 \\
\hline infections & $20(14.1)$ & $7(4.9)$ & $4(2.9)$ & $4(3.7)$ & $2(2.5)$ & $5(15.6)$ & $1(4.2)$ & 0 \\
\hline $\begin{array}{l}\text { Post-infusion sys- } \\
\text { temic reactions } \\
\text { Depression/sui- } \\
\text { cide/ self-injury }{ }^{\dagger}\end{array}$ & $9(6.3)$ & $4(2.8)$ & $2(1.5)$ & $1(0.9)$ & $1(1.3)$ & 0 & 0 & 0 \\
\hline
\end{tabular}

${ }^{*}$ Death from an $\mathrm{AE}$ of endocarditis that began $\sim 1$ month after the exit visit; the investigator considered it to be unrelated to the study drug

${ }^{\dagger}$ No serious suicide/self-injury AEs were reported during the study

Results: Overall, 142 pts were enrolled (Japan $n=72$; Korea $n=70), 104$ (73.2\%) completed the study, 1 (0.7\%) died and $37(26.1 \%)$ withdrew.

Overall, 139 (97.9\%) pts had $\geq 1$ adverse event (AE) (Table). Most frequent AEs included: nasopharyngitis $(60.6 \%)$; headache $(28.2 \%)$; cough, herpes zoster and viral upper respiratory tract infection (18.3\% each). Serious AEs (SAEs) occurred in $48(33.8 \%)$ pts. Most common SAEs were infections and infestations, reported in $24(16.9 \%)$ pts (Table). During this study, the annual incidence of AEs, including SAEs and AESI, remained stable or declined, with no trends of clinical concerns regarding the incidence of Grade 3 or 4 values for laboratory parameters. There was 1 transient positive immunogenicity result of no clinical concern.

The proportion of SRI4 responders was $47.8 \%$ at Year 1 (Week 24) and tended to increase numerically up to $84.6 \%$ at Year 7 (Week 48). The proportion of pts with a $\geq 4$-point decrease from baseline in SELENA-SLEDAI score numerically increased from 51.5\% at Year 1 (Week 24) to 84.6\% at Year 7 (Week 48). Proportion of pts with no PGA worsening was $91.3-100 \%$ and the proportion with no new BILAG 1A/2B organ domain scores was 93.3-100\% up to Year 7 (Week 48). A total of $21(14.8 \%)$ pts had 24 severe SFI flares.

Conclusion: BEL was well tolerated as add-on therapy to SST for $\leq 7$ years in pts with SLE from Japan/Korea. Safety results were consistent with the known BEL safety profile.

Study funding: GSK.

Disclosure of Interests: Yoshiya Tanaka Grant/research support from: Received research grants from Asahi-Kasei, Mitsubishi-Tanabe, Chugai, Takeda, Sanofi, Bristol-Myers, UCB, Daiichi-Sankyo, Eisai, Ono, Speakers bureau: Received speaking fees and/or honoraria from Daiichi-Sankyo, Astellas, Chugai, Eli Lilly, Pfizer, AbbVie, YL Biologics, Bristol-Myers, Takeda, Mitsubishi-Tanabe, Novartis, Eisai, Janssen, Teijin, Sang-Cheol Bae: None declared, Damon Bass Shareholder of: GSK, Employee of: GSK, Myron Chu Shareholder of: GSK, Employee of: GSK, Paula Curtis Shareholder of: GSK, Employee of: GSK, Kathleen DeRose Shareholder of: GSK, Employee of: GSK, Beulah Ji Shareholder of: GSK, Employee of: GSK, Regina Kurrasch Shareholder of: GSK, Employee of: GSK, Jenny Lowe Shareholder of: GSK, Employee of: GSK, Paige Meizlik Shareholder of: GSK, Employee of: GSK, David Roth Shareholder of: GSK, Employee of: GSK DOI: 10.1136/annrheumdis-2020-eular.5783

\section{SAT0194 LACK OF EFFICACY OF RIVAROXABAN IN THE TREATMENT OF ANTIPHOSPHOLIPID SYNDROME AND CLINICAL SIGNIFICANCE OF ANTIPHOSPHOLIPID ANTIBODIES}

S. Vardanyan ${ }^{1}$, K. Ginosyan ${ }^{2}$, V. Vardanyan ${ }^{1}$, A. Sargsyan ${ }^{2}$, A. Simonyan ${ }^{2}$

1 "Mikaelyan"Institute of Surgery, Yerevan, Armenia; ${ }^{2}$ Yerevan State Medical University, Yerevan, Armenia
Background: Chronic anticoagulation with vitamin K antagonists (VKA) is the standard treatment to prevent thrombotic events in antiphospholipid syndrome (APS). But in recent years treatment schemes began to include rivaroxaban. Use of direct oral anticoagulants (DOAC) is an attractive and often preferred alternative to VKAs in other medical settings owing to greater ease of use, fewer food and drug interactions, and lower bleeding risks [1].However, according to last guidelines, rivaroxaban should not be used in patients with triple aPL positivity due to the high risk of recurrent events [2].

Objectives: 1.To determine the risk of recurrent thrombosis in single or double positive APS patients treated with rivaroxaban.

2.Find out possible association between presence of particular antiphospholipid antibodies or high level of lupus anticoagulant (LA) and type of vascular events. Methods: 33 patients with confirmed APS (25 female (75.8\%), 8 male $(24.2 \%)$, mean age $43.2 \pm 11.6$ years) were included in the study. $17(51.5 \%)$ of investigated patients had primary APS, in remaining $16(48.5 \%)$ APS was included in the framework of SLE. $18(54.5 \%)$ patients were treated with warfarin $2.5-7.5 \mathrm{mg} /$ daily, $15(45.5 \%)$ patients - with rivaroxaban $20 \mathrm{mg} /$ daily for a follow-up period of 12 months. The data is introduced as odds ratios (OR) with $95 \%$ confidence interval $(\mathrm{Cl})$. The results were considered significant when $\mathrm{p}<0.05$.

Results: At baseline 21 (63.6\%) patients had history of arterial thrombosis, 10 $(30.3 \%)$ - venous thrombosis, $17(51.5 \%)$ - pregnancy loss. According to results of serum immunology check, $29(87.9 \%)$ patients were anticardiolipin antibody (ACA) positive, 9 (27.3\%) - LA positive, 19 (57.6\%) - anti-32-glycoprotein antibodies (anti-ß2-gp) positive; 20 (60.6\%) patients were double positive (12 (36.4\%) of them had positive ACA and anti-B2-gp, 6 (18.2\%) - ACA and LA, and 2 (6.1\%) - anti-ß2-gp and LA), 4 (12.1\%) patients were triple positive.

No association between vascular event and/or pregnancy loss in patients with single positive ACA was found. We have found positive association between arterial thrombosis and single positive anti-ß2-gp (OR /CI 95\%/ = 5.0 /2.08 - 23.06/, $\mathrm{p}<0.05$ ), positive association between positive LA and venous thrombosis (OR $/ \mathrm{Cl} 95 \% /=10 / 1.7-57.7 /, \mathrm{p}<0.05)$, strong positive association between positive $\mathrm{LA}$ and thromboembolism of pulmonary artery (OR $/ \mathrm{Cl} 95 \% /=46.0 / 4.0-525.1 /$, $\mathrm{p}<0.001$ ), negative association between positive LA and pregnancy loss (OR /Cl $95 \% /=0.06 / 0.03-0.1 /, \mathrm{p}<0.01$ )

Risk of thrombosis and/or pregnancy loss was not significantly increased in double positive patients, but triple positive patients had increased risk of venous thrombosis (OR /Cl 95\%/ =9.4/3.2 - 105.8/, p<0.04).

Recurrent thrombosis was detected in 16 patients: 2 patients $(12.5 \%)$ were on warfarin, $14(87.5 \%)$ - on rivaroxaban (10 (71.4\%) arterial thrombosis, $4(28.6 \%)$ venous thrombosis).

No association between warfarin $2.5-7.5 \mathrm{mg} /$ daily and occurrence of recurrent thrombosis was detected. An association between use of warfarin and increased risk of bleeding was found, but the risk was not significant $(\mathrm{OR} / \mathrm{Cl} 95 \% /=7.0 / 0.7$ - 66/, p= 0.09). Rivaroxaban $20 \mathrm{mg} /$ daily was associated with recurrent thrombosis not only for triple positive patients $(p<0.02)$, but also in double positive patients (OR $/ \mathrm{Cl} 95 \% /=21.3 / 1.8-251 /$, p $<0.04)$.

Conclusion: Rivaroxaban does not prevent recurrent thrombosis not only in triple positive patients, but also in single and double positive APS patients. Type of antiphospholipid antibodies can be predictive for the type of further vascular event.

References:

[1] Vittorio Pengo, Gentian Denas, Giacomo Zoppellaro et al.Rivroxaban vs warfarin in high risk patients with antiphospholipid syndrome, Blood. 2018 Sep 27; 132(13); 1357-1358

[2] EULAR recommendations for the management of antiphospholipid syndrome in adults, Annals of the Rheumatic Diseases/ Volume 78: Issue 10:1296-1304.

Disclosure of Interests: None declared

DOI: 10.1136/annrheumdis-2020-eular.3822

\section{SAT0195 1 ABNORMITY TFH SUBSETS INDICATE DISEASE ACTIVITY WHILE SIROLIMUS THERAPY RESTORES THE PD-1+ICOS+TFH/ACTIVATED TFR BALANCE IN PRIMARY SJOGREN'S SYNDROME PATIENTS}

Y. Wang ${ }^{1}$, J. Luo ${ }^{1}$, C. Gao ${ }^{2}$, X. C. Zhao ${ }^{1} .{ }^{1}$ The Second Hospital of Shanxi Medical University, Taiyuan, China; ${ }^{2}$ Brigham and Women's Hospital, Boston, United States of America

Background: Immune imbalance between follicular helper T (Tfh) cells and follicular regulatory $\mathrm{T}(\mathrm{Tfr})$ cells is a characteristic of primary Sjogren's syndrome (pSS) [1]. The heterogeneity among Tfh and Tfr can be elucidated by separating them into different subsets based on the expression molecular characteristics.

Objectives: The aim of this study was to investigate the role of Tfh and Tfr subsets and to evaluate the effects of sirolimus on these cells.

Methods: In this study, we enrolled 51 pSS patient and 26 healthy controls (HCs), and analyzed the frequencies and absolute counts of circulating Tfh and Tfr subsets, and serum levels of cytokines. Within these patients, analyses of above $T$ 
cells in twelve patients before and after treatment with sirolimus. Clinical indicators and correlations with follicular T cells were systematically analyzed. The diagnostic value for $C D 4+C X C R 5+T$ cells was evaluated by the areas under the receiver operating characteristic curves (AUC).

Results: Patients with pSS had higher frequencies and absolute numbers of PD-1+ICOS+Tfh cells, but lower levels of activated Tfr cells cells, thereby resulting in elevated ratios of $\mathrm{PD}-1+\mathrm{ICOS}+\mathrm{Tfh} /$ activated Tfr. In addition, PD-1+Tfh cells levels were lower in pSS patients than in HCs. Interestingly, the ratio of $\mathrm{PD}-1+\mathrm{ICOS}+\mathrm{Tfh} /$ activated Tfr was a strong predictor of $\mathrm{pSS}$ diagnosis. However, sirolimus therapy resulted in significant reductions in PD-1+lCOS+Tfh cells and the PD- $1+\mathrm{ICOS}+\mathrm{Tfh} /$ activated Tfr ratio in pSS patients. We also found increased numbers of PD-1+ICOS+Tfh cells were associated with B cells, while decreased numbers of Tfr and their subsets were strongly associated with aTreg cells in pSS patients. The ESSDAI [2] was positively correlated with PD-1+ICOS+Tfh cell frequency, but was negatively correlated with PD-1+Tfh cell count.

Conclusion: These findings suggest that the PD-1+ICOS+Tfh cell:activated Tfr cell ratio and PD-1+Tfh cells constitute potential novel biomarkers for pSS, and Tfr cells and subsets resemble derived aTreg cells. Furthermore, the PD-1+ICOS+Tfh cells as a biomarker of disease activity and provide new ground to verify the therapeutic implications of sirolimus as an innovative drug in pSS.

References:

[1] Fonseca VR, Romão VC, Agua-Doce A, Santos M, López-Presa D, Ferreira AC, et al. The Ratio of Blood T Follicular Regulatory Cells to T Follicular Helper Cells Marks Ectopic Lymphoid Structure Formation While Activated Follicular Helper T Cells Indicate Disease Activity in Primary Sjogren's Syndrome. Arthritis Rheumatol 2018; 70:774-784.

[2] Seror R, Ravaud P, Bowman SJ, Baron G, Tzioufas A, Theander E, et al. EULAR Sjogren's syndrome disease activity index: development of a consensus systemic disease activity index for primary Sjogren's syndrome. Ann Rheum Dis 2010; 69:1103-9.

Disclosure of Interests: None declared

DOI: 10.1136/annrheumdis-2020-eular.2159

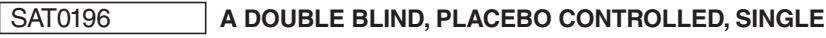 ASCENDING DOSE (SAD) AND MULTIPLE ASCENDING DOSE (MAD) STUDY OF ALPN-101, A FIRST-IN- CLASS DUAL ICOS/CD28 ANTAGONIST, IN HEALTHY VOLUNTEERS (HV)}

J. Yang ${ }^{1}$, J. Hillson ${ }^{1}$, J. Lickliter ${ }^{2}$, K. Manjarrez ${ }^{1}$, A. Tercero ${ }^{1}$, J. Wiley ${ }^{1}$, G. Means ${ }^{1}$, R. Sanderson ${ }^{1}$, K. Carley ${ }^{1}$, S. L. Peng ${ }^{1} .{ }^{1}$ Alpine Immune Sciences Inc, Seattle, United States of America; ${ }^{2}$ Nucleus Network, Melbourne, Australia

Background: ALPN-101 (ICOSL vlgD-Fc) is an Fc fusion protein of a human inducible T cell costimulatory ligand (ICOSL) variant immunoglobulin domain (vlgD ${ }^{\mathrm{TM}}$ ) designed to inhibit simultaneously the CD28 and ICOS inflammation pathways (1). ALPN-101 is effective in preclinical studies of lupus, arthritis, and Sjögren's, and shows greater activity than single pathway inhibitors $(2,3,4)$. It is in development for the treatment of multiple rheumatic and other inflammatory diseases.

Objectives: To evaluate the safety, pharmacokinetics (PK), and pharmacodynamics (PD) of ALPN-101 in HV

Methods: This was a first-in-human study of ALPN-101 (NCT03748836). $72 \mathrm{HV}$ were allocated 4:2 to single intravenous (IV) or subcutaneous (SC) doses of ALPN101: placebo at $0.001-10 \mathrm{mg} / \mathrm{kg} ; 24 \mathrm{HV}$ were allocated $6: 2$ to repeated IV doses of up to $1 \mathrm{mg} / \mathrm{kg}$ weekly $\times 4$. Subjects were followed for 28 (SAD) or 49 (MAD) days to assess safety, PK, target saturation (TS) on T cells, circulating cytokines and PD, the latter based on suppression of IgG responses to keyhole limpet hemocyanin (KLH). Results: ALPN-101 was generally well-tolerated, with no treatment related serious adverse events, no cytokine release, no clinical immunogenicity, and no adverse trends in safety laboratories. Overall, adverse events were reported in $74.2 \%$ of subjects on ALPN-101 and $66.7 \%$ of subjects on placebo. All events were mild or moderate and resolved without sequelae. Dose-dependent increase in ALPN-101 exposure was observed from 0.012 to $10 \mathrm{mg} / \mathrm{kg}$. The estimated $t_{1 / 2}$ was 2-8.6 days over $0.3-10 \mathrm{mg} / \mathrm{kg}$. SC bioavailability was $\sim 60 \%$ at $3 \mathrm{mg} / \mathrm{kg}$. Minimal to modest accumulation was observed with repeat IV dosing. The TS at $\mathrm{C}_{\max }$ increased with dose between $0.001-0.03 \mathrm{mg} / \mathrm{kg}$; thereafter the duration of high level TS (>95\%) increased with dose (Figure 1). The duration of suppression of IgG anti-KLH response paralleled the duration of high level TS (Figure 2).

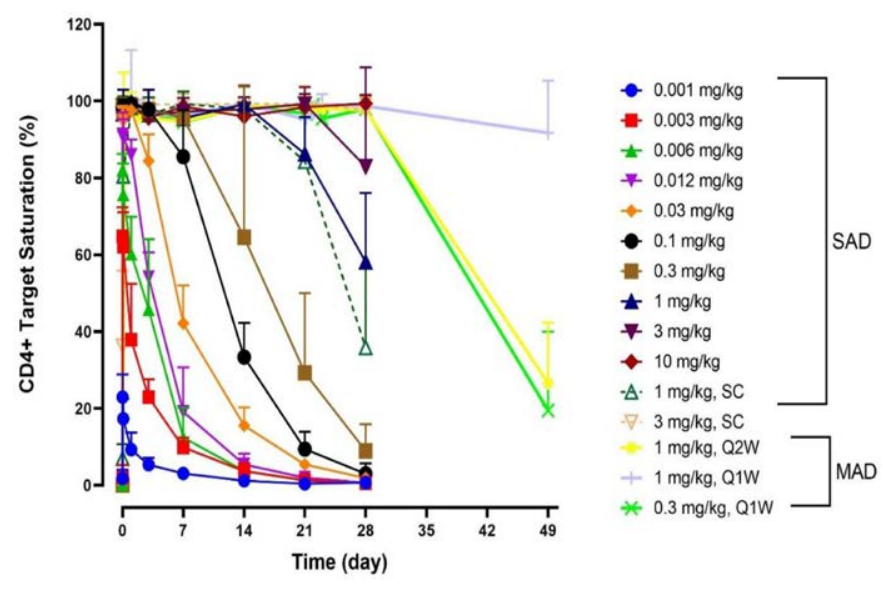

Figure 1. Mean + SD Target Saturation of ALPN-101 on Circulating CD4+T Lymphocytes

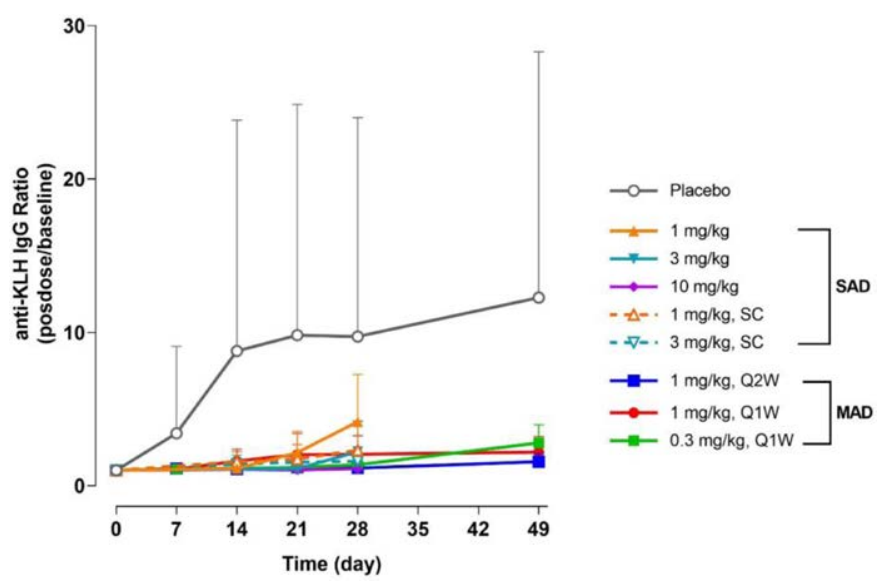

Figure 2. Mean + SD Serum Anti-KLH IgG Change Relative to Baseline

Conclusion: ALPN-101 was well tolerated when administered as single doses up to $10 \mathrm{mg} / \mathrm{kg}$ or as repeated doses of up to $1 \mathrm{mg} / \mathrm{kg}$ weekly for 4 weeks, exhibiting dose-dependent PK, TS and PD including the inhibition of antibody responses to $\mathrm{KLH}$ immunization. These findings support future studies to evaluate the efficacy of ALPN-101 in multiple rheumatic and other inflammatory diseases.

\section{References:}

[1] Levin SD et al. Frontiers in Immunology 2020; 10:3086

[2] Evans L et al. Arthritis and Rheumatology 2019:71: Supplement: Abstract 1531

[3] Dillon S et al. Arthritis and Rheumatology 2018:70: Supplement: Abstract 136

[4] Dillon S et al. Arthritis and Rheumatology 2019:71: Supplement: Abstract 2416 Disclosure of Interests: Jing Yang Shareholder of: Alpine Immune Sciences, Inc., Employee of: Alpine Immune Sciences, Inc., Jan Hillson Shareholder of: Alpine Immune Sciences, Inc., Employee of: Alpine Immune Sciences, Inc., Jason Lickliter Consultant of: AUD 2500 from QBiotics for participation in an expert review panel for development of their oncology phase 1 trial (in Nov 2015), Kristi Manjarrez Shareholder of: Alpine Immune Sciences, Inc., Employee of: Alpine immune sciences, Inc., Almudena Tercero Shareholder of: Alpine Immune Sciences, Inc., Employee of: Alpine Immune Sciences, Inc., Jennifer Wiley Shareholder of: Alpine Immune Sciences, Inc., Employee of: Alpine Immune Sciences, Inc., Gary Means Shareholder of: Alpine Immune Sciences, Inc., Employee of: Alpine Immune Sciences, Inc., Russell Sanderson Shareholder of: Alpine Immune Sciences, Inc., Employee of: Alpine Immune Sciences, Inc., Kay Carley Shareholder of: Alpine Immune Sciences, Inc., Employee of: Alpine Immune Sciences, Inc., Stanford L. Peng Shareholder of: Alpine Immune Sciences, Inc., Employee of: CMO and President of Alpine Immune Sciences, Inc. DOI: 10.1136/annrheumdis-2020-eular.2388 